East African Medical Journal Vol. 85 No. 9 September 2008

METHYLERGOMETRINE POISONING IN THE NEWBORN: REPORT OF TWO CASES

C.C. Enweronu-Laryea, MRCP(U.K), MRCPCH(U.K), FGCP(Ghana), Lecturer, Department of Child Health, University of Ghana Medical School, P. O. Box 4236, Accra, Ghana, I. Aryee, MBChB (Ghana), Resident, A. Frimpong-Barfi, MBChB (Ghana), Resident, Department of Child Health, Korle Bu Teaching hospital, Accra, Ghana and O. P. Rodrigues, FRCPCH(U.K), FWACP, FGCP(Ghana), Professor, Department of Child Health, University of Ghana Medical School, P. O. Box 4236, Accra, Ghana

Request for reprints to: Dr. C.C. Enweronu-Laryea, Department of Child Health, University of Ghana Medical School, P. O. Box 4236, Accra, Ghana

\title{
METHYLERGOMETRINE POISONING IN THE NEWBORN: REPORT OF TWO CASES
}

\author{
C.C. ENWERONU-LARYEA, I. ARYEE, A. FRIMPONG-BARFI and O. P. RODRIGUES
}

\begin{abstract}
SUMMARY
Methylergometrine is probably the most commonly used drug in obstetric care at all levels of the health care system. Many communities in Africa lack skilled birth attendants and adequate health systems; medication errors are more likely to occur and go unreported in these settings. The morbidity and mortality that result from these errors can be reduced if health care workers are better informed. We report two cases of medication error with methylergometrine and suggest guidelines for health care workers at the primary and secondary levels of health care.
\end{abstract}

\section{INTRODUCTION}

Errorsin the administration of drugs occur commonly and are a leading cause of mortality and morbidity (1). The true incidence in developing countries especially in sub-Saharan Africa is unknown. Most errors cause no harm, but the administration of the wrong dose or the wrong drug may have life threatening effects.

Methylergometrine, a semi-synthetic derivative of the amine-alkaloid group of ergot compounds has uterotonic and vasoconstrictive effects that has been widely used in the prevention of postpartum haemorrhage since the 1950s (2). It is usually kept in labour rooms for immediate parenteral use during the last stage of labour.

A limited number of cases of ergot poisoning in thenewbornhavebeen reported worldwide(3-5). Most cases resulted from confusion of methyergometrine with vitamin $\mathrm{K}$ or naloxone. Affected newborns present with respiratory depression, encephalopathy, seizures and disturbances in the peripheral circulation. Death is usually caused by respiratory failure. We report two cases of methylergometrine poisoning referred to the neonatal intensive care unit of Korle Bu Teaching Hospital, Accra, Ghana.

\section{CASE REPORTS}

Case 1: A 3.3 kilogram, full term female infant was born by spontaneous vaginal delivery (SVD) after an uncomplicated pregnancy. The Apgar scores were 6 and 8 at one and five minutes respectively; she required oropharyngeal suctioning and facial oxygen for resuscitation at birth. Soon after birth a nurse assistant administered $1 \mathrm{ml}$ of methylergometrine (0.5 mg of ergometrine maleate) intramuscularly, believing it to be vitamin $\mathrm{K}$. The error was recognised immediately, but the nurses were not sure of what to do; hence intramuscular hydrocortisone was administered. Within 30 minutes the infant became cyanosed, with shallow breaths and had an apneic event. She was referred to the neonatal intensive care unit (NICU) within an hour after the incident on account of respiratory distress. The nurse who brought the infant confided to a NICU staff that methylergometrine was inadvertently given to the infant, but vitamin $\mathrm{K}$ was not given.

The respiratory effort was shallow at 23 breaths per minute, heart rate 162 beats per minute, and blood pressure $61 / 34 \mathrm{mmHg}$ (mean $42 \mathrm{mmHg}$ ). She had a weak cry, absent moro reflex, and normal sucking reflex. Her breathing improved with bag and mask ventilation. Vitamin $\mathrm{K}$ was given. At three hours the infant had frequent episodes of hypoxia requiring intermittent bag and mask ventilation. At six hours, persistenthypoventilation necessitated endotracheal intubation and mechanical ventilation. At eight hours blood pressure was $68 / 47 \mathrm{mmHg}$ (mean 60 $\mathrm{mmHg}$ ); sodium nitroprusside (SNP) infusion was commenced, with the infusion rate titrated according 
to blood pressure control. She first passed urine at nine hours after birth, and urine output remained normal thereafter.

She had no clinical seizures. Blood culture was negative. Antibiotics were administered for five days. The infant was ventilated for 28 hours and SNP was stopped after 57 hours. A complete blood count on admission was normal. Renal function was slightly deranged on day three $\left(\mathrm{Na}^{+} 132 \mathrm{mmol} / \mathrm{L}\right.$, $\mathrm{K}^{+} 4.2 \mathrm{mmol} / \mathrm{L}$, Urea $8.4 \mathrm{mmol} / \mathrm{L}$, and creatinine $83 \mu \mathrm{mol} / \mathrm{L}$ ) but normalised before discharge. Neurological examination was normal on day three and she was breastfeeding on day four. The infant was discharged home on day eight. Outpatient follow-up at six weeks showed no abnormality.

Case 2: A full term infant weighing 3.6 kilogram was referred to NICU at the age of 30 minutes after a normal SVD with persistent cyanosis. The referring nurse confided to a NICU nurse about inadvertent administration of ergometrine at birth by a student nurse. The infant was cyanosed, but had no other abnormal findings on physical examination. Vitamin $\mathrm{K}$ was given. He was admitted for observation and supplemental oxygen was administered. He had a generalised seizure at the age of two hours. Phenobarbitone $20 \mathrm{mg} / \mathrm{kg}$ was administered. He subsequently had another suspected convulsion on day one and none thereafter. His blood pressure, urine output, blood electrolytes, urea and creatinine remained normal. Supplemental oxygen was discontinued on day three, and breast feeding was commenced. He was discharged on day seven. Follow-up at three months showed no neurological abnormality. The infant has not reported for subsequent follow-up.

\section{DISCUSSION}

Our patients presented with respiratory depression and seizures; similar clinical manifestations as documented by other workers. Both patients survived. Death from ergometrine poisoning has been reported (6), but majority of newborns treated in tertiary health facilities survive with normal neurological function (7). Many affected newborns in Africa may not be referred to tertiary health facilities.

The $\alpha$-adrenergic effect of ergometrine, its direct constrictive effect on vascular smooth muscle and the associated loss of central control of vasomotor tone lead to most of the clinical manifestations of ergot poisoning (8). The ventilation perfusion mismatch resulting from pulmonary vasoconstriction may explain the respiratory signs in reported cases. The marked cyanosis is believed to result from profound venoconstriction. The vasoconstrictive effects on mesenteric and renal vasculature lead to acute endorgan circulatory compromise. The neurological effects result from vasoconstriction and the direct effect of ergometrine on cortical neurons (9).

There was no documentation of inadvertent ergometrine administration in the referral letters of these two cases; the nurses who brought the infants did not confide to the admitting doctor but to another NICU staff they knew personally. Other workers have shown that when these errors are recognised they are not usually documented or reported because of fear of disciplinary action (10).

Prevention of this potentially life-threatening medication error is possible by: (a) Avoidance of vitamin $\mathrm{K}$ administration to the newborn in the first few minutes of life when skilled health care workers (HCW) are busy with the mother. (b) Keeping vitamin Kand naloxone in separate clearly labeled areas away from methylergometrine. (c) Use of oral vitamin K.(d) Cross-checking all medication with another member of staff before administering it to patients.

The poor outcome of medication errors may be reduced by early recognition and appropriate intervention with antidotes or supportive care. We recommend that the following steps betaken assoon as the inadvertent administration of methylergometrine in the newborn is recognised.

(i) Vitamin $\mathrm{K}$, the drug intended for the newborn should be administered.

(ii) Thebaby should benursed in oxygen, if available, while urgent plans are made to transfer the infant to a tertiary centre as the onset of symptoms may be as long as three hours.

(iii) If the expertise to insert an intravenous line is available at the health facility; this should be done as soon as possible as vascular access may be difficult later. However, this procedure must not delay transfer.

(iv) Seizures should be treated promptly with phenobarbitone $20 \mathrm{mg} / \mathrm{kg}$.

(v) A senior member of staff should counsel the parents and the health worker who administered the medication as this event causes significant emotional trauma to both.

Many HCW in Africa lack knowledge about the drugs they administer to patients and the consequences of medication error there-of. As a result most medication errors may be unrecognised and therefore unreported; downplaying the event when recognised or inappropriately management as in Case 1 is more likely. These actions delay or prevent appropriate referral and management of affected patients thus increasing morbidity or mortality.

Less punitive system-centred approach to improve drug administration safety has been shown (11) to increase reporting of drug errors by HCW.Such approach coupled with continuing medicaleducation of HCW on drug administration safety may reduce morbidity and mortality from medication errors in Africa. 


\section{REFERENCES}

1. Kohn, L.T., Corrigan, J.M. and Donaldson, M.S. Committee on Quality of Health Care in America: Institute of Medicine. To err is human: Building a safer health system. National Academy of Sciences. Washington, D.C. National Academies Press; 2000.

2. Leff, M. The role of adrenalin (epinephrine) in labor and the use of an adrenolytic drug to prevent postpartum hemorrhage; observations based on 3,500 cases. Am. J. Obstet. Gynecol. 1953; 65: 278-281.

3. Aeby, A., Johansson, A., De Schuiteneer, B. and Blum, D. Methylergometrine poisoning in children: Review of 34 cases. J. Toxicol. Clin. Toxicol. 2003; 41: 249-253.

4. Donatini, B., Le Blaye, I. and Krupp. P. Inadvertent administration of uterotonics to neonates. Lancet.1993; 341: 839-840.

5. Brereteon-Stiles, G.G., Winship, W.S., Goodwin, N.M., et al. Accidental administration of syntometrine to a neonate. S. Afr. Med. J. 1972; 46:2052.

6. Yalaburgi, S.B. and Mohapatra, K.C. Accidental administration of syntometrine to a neonate resulting in death. East Afr. Med. J. 1982; 59: 698-700.
7. Dargaville, P.A. and Campbell, N.T. Overdose of ergometrine in the newborn infant: Acute symptomatology and long-term outcome. J. Paediatr. Child. Health. 1998; 34:83-89.

8. Peroutka, S.J. Drugs effective in the therapy of migraine. In: Hardman J.G., Limbird L.E., Molinoff P.B., Ruddon R.W., eds. Goodman \& Gilman: The Pharmacological Basis of Therapeutics. New York, NY: McGraw Hill; 1996; 487-202.

9. Krnjevic, K. and Phillis, J.W. Action of certain amines on cerebral cortical neurons. Brit. J. Pharmacol. 1963; 20: 471-490.

10. Mrayyan, M.T., Shishani, K. and Al-Faouri, I. Rate, causes and reporting of medication errors in Jordan: nurses' perspectives. J. Nursing Management. 2007; 15: 659-670.

11. Anderson, D.J. and Webster, C.S. Asystems approach to the reduction of medication error on the hospital ward. J. Advanced Nursing. 2001; 35: 34-41. 